\title{
Vaginal Adenosquamous Carcinoma
}

National Cancer Institute

\section{Source}

National Cancer Institute. Vaginal Adenosquamous Carcinoma. NCI Thesaurus. Code C40260.

A carcinoma that arises from the vagina and is characterized by the presence of malignant glandular and malignant squamous epithelial components. 